\title{
Termodinâmica aplicada à Bioquímica
}

\author{
Edmundo Gomes de Azevedo a
}

\section{Introdução}

As ideias básicas da termodinâmica clássica foram estabelecidas em meados do século passado. Contudo, a sua aplicação aos fenómenos químicos fez-se só a partir de 1870 devido principalmente aos trabalhos de W. Gibbs, tornando-se a sua aplicação mais generalizada a partir da publicação em 1923 do livro de Lewis e Randall "Thermodynamics».

A palavra "Termodinâmica" está associada à transformação do calor em trabalho mecânico. Não é de estranhar por isso que tenha demorado algum tempo o estabelecimento das técnicas e métodos que permitiram a sua aplicação aos fenómenos químicos. Hoje em dia a termodinâmica é uma ciência fundamental que serve de suporte à química e à engenharia química modernas. A termodinâmica química tornou-se num ramo muito poderoso da termodinâmica geral e fornece resultados úteis para a indústria química, a qual tem um papel essencial na economia e no desenvolvimento social modernos.

O sucesso e a importância das aplicaçðes da termodinâmica química fizeram com que a termodinâmica fosse também aplicada a outros ramos da ciência. As leis e relações fundamentais da termodinâmica são gerais e podem ser aplicadas na resolução de problemas de astronomia, geologia ou biologia. As relaçōes termodinâmicas que se usam na determinação do diagrama de fases do material que se encontra no interior da terra a $200 \mathrm{~km}$ de profundidade são as mesmas que se usam para estabelecer a composição das nuvens de Júpiter - a termodinâmica é uma ciência multidisciplinar.

\section{Relações com a Bioquímica e Biofísica}

A termodinâmica envolve o estudo da utilização e conservação da energia pelo que está intimamente relacionada com os processos bioquímicos. A termodinâmica regula a aquisição de energia contida nos alimentos ingeridos pelos organismos vivos, assim como o seu armazenamento no organismo e a sua libertação na actividade metabólica. Os seres vivos transformam energia química em energia mecânica (como acontece na contracção dos músculos) e as relaçōes termodinâmicas são fundamentais para a compreensão destas transformaçס̄es. A energia envolvida na biosíntese das proteínas é igualmente ditada pelas leis da termodinâmica.

Uma célula viva não é mais que um reactor químico muito complexo onde podem ter lugar mais de 1000 reacçסes independentes, as quais podem ocorrer espon- taneamente quando catalisadas pelos enzimas adequados. A cinética destas reaç̧ōes bioquímicas está igualmente dependente de dados termodinâmicos. Porém, muitas outras reacçōes de grande importância, como sejam as biosinteses dos ácidos nucleicos e das proteínas, não ocorrem espontaneamente e devem acoplar-se a outras reacçð̄es espontâneas, as quais devem fornecer as energias de Gibbs necessárias para que se efectuem esses processos sintéticos.

Compreende-se assim a importância que a termodinâmica desempenha na compreensão dos processos bioquímicos, de modo análogo ao que se passa com, por exemplo, os processos químicos.

\section{Processos químicos e processos bioquímicos}

A termodinâmica química tem sido largamente utilizada no projecto e desenvolvimento de muitos processos químicos como, por exemplo, no fabrico de produtos derivados do petróleo.

A Fig. 1a exemplifica um desses processos de fabrico. Trata-se do esquema simplificado de um processo industrial para o fabrico de p-xileno a partir do petróleo. (O p-xileno é um produto químico muito importante pois é utilizado como intermediário na produção do ácido tereftálico e do tereftalato dimetílico, os quais são a matéria-prima utilizada no fabrico de fibras poliésteres como, por exemplo, o Dracon).

As unidades mais importantes apresentadas na Fig. 1a referem-se a operaçōes unitárias, nomeadamente a destilação. As unidades designadas na Fig. 1a por "debutanizer", "regenerator", "toluene/xylenes" e "'xylene recovery" são de facto colunas de destilação onde se separam os componentes de acordo com a sua volatilidade. Por exemplo, uma das unidades de extracção separa o benzeno e tolueno dos xilenos e aromáticos mais pesados. Além da destilação estão ainda representados na Fig. 1a outros processos de separação, como a separação líquido-vapor, a extracção líquido-líquido e a criatalização.

O projecto e o funcionamento de processos como o representado na Fig. 1a deve muito à termodinâmica química. Para esse fim a termodinâmica utiliza os dados termofísicos dos componentes puros (e suas misturas) envolvidos no processo, assim como muitos métodos de correlação e modelos termodinâmicos necessários para descrever o equilibrio termodinâmico

\footnotetext{
- Centro de Química Estrutural, Instituto Superior Técnico, Av. Rovisco Pais, 1096 Lisboa, Portugal.
} 
a)

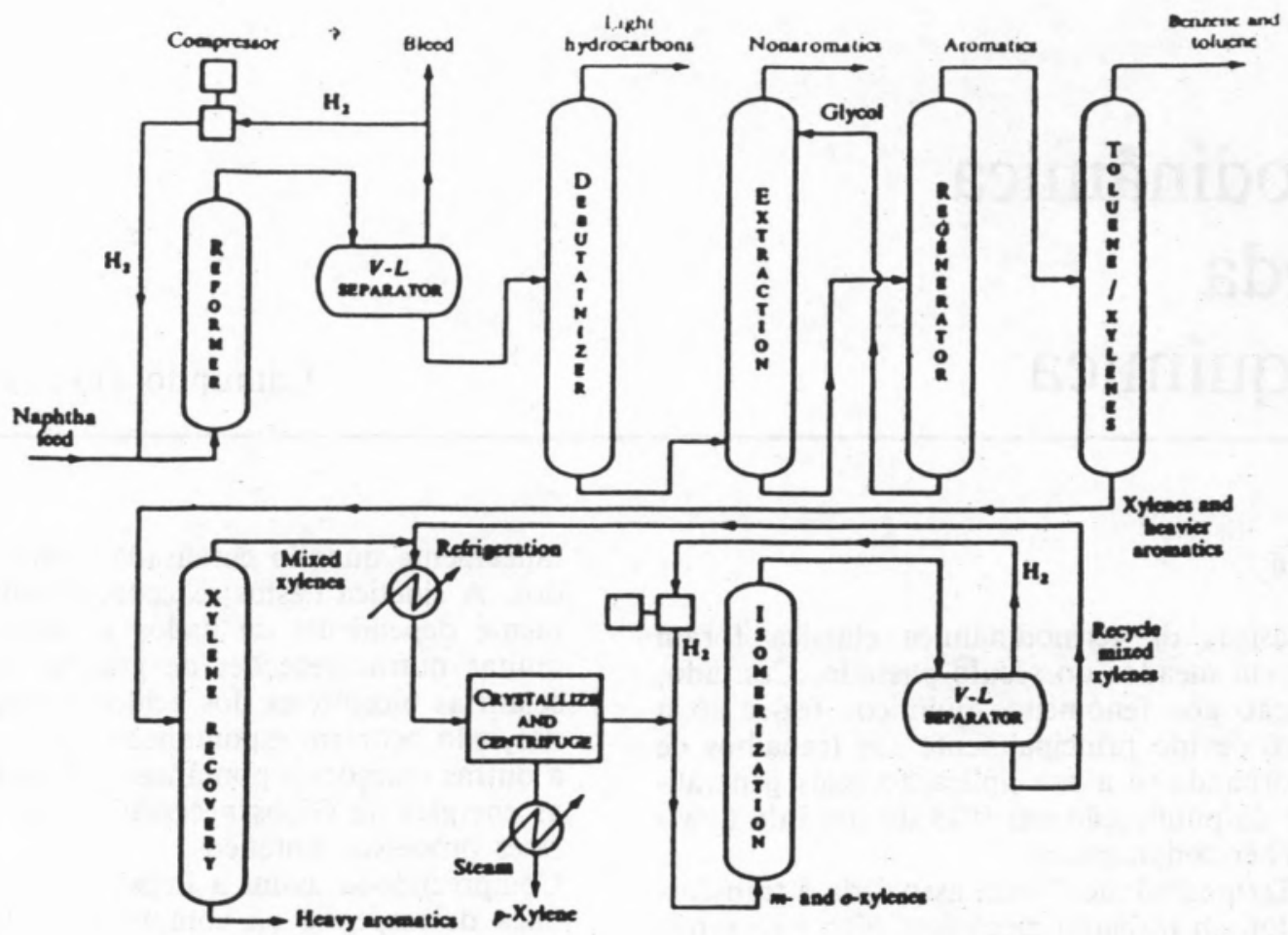

b)

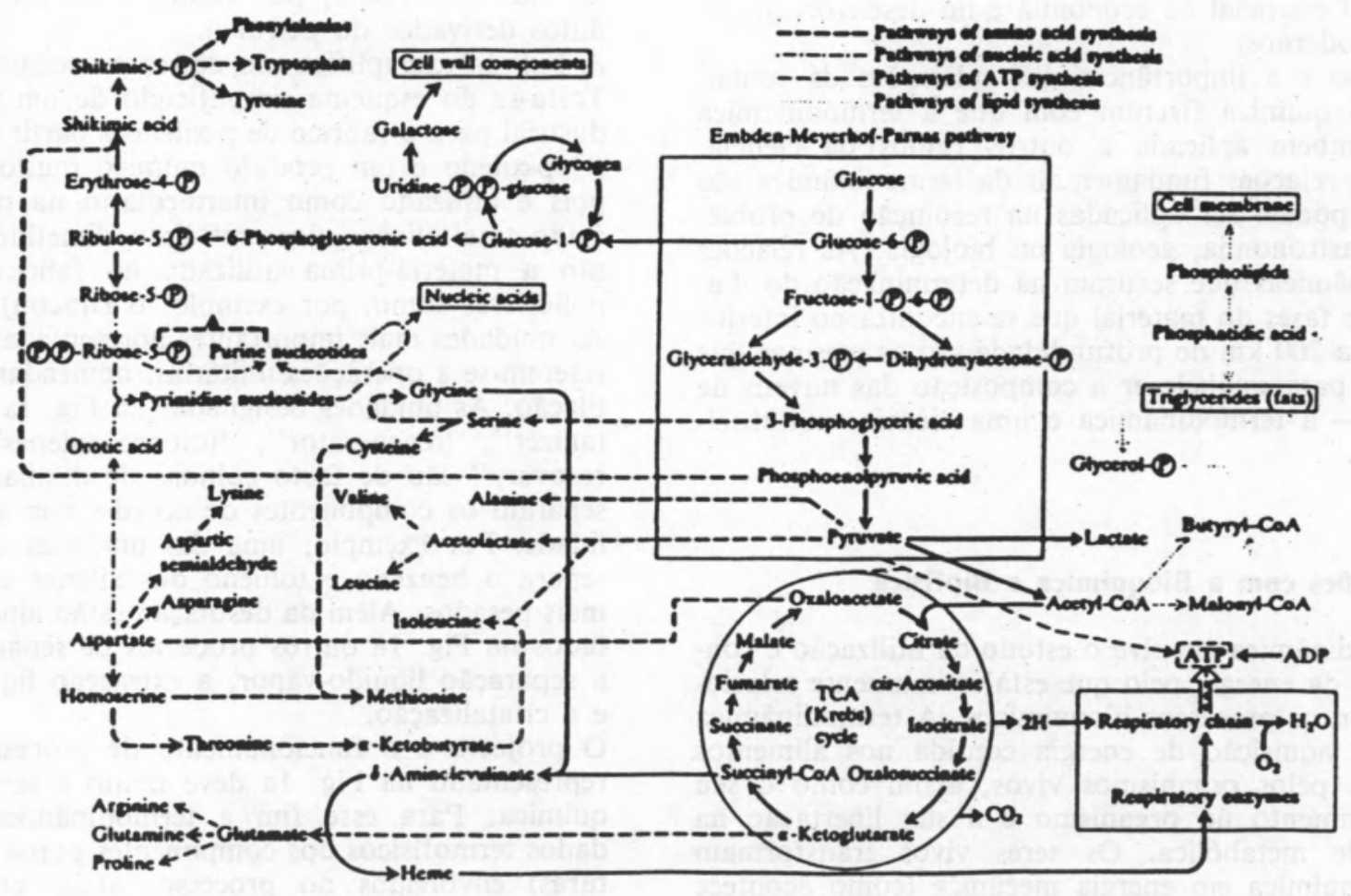


das diversas fases presentes. Nos processos químicos tradicionais sabem-se as propriedades termofísicas dos fluidos (ou existem métodos de previsão alternativos) e são bem conhecidas as técnicas para a descrição quantitativa do equilibrio entre as diversas fases.

A situação é bem diferente quando se estudam os processos bioquímicos em equilíbrio. A Fig. 1b mostra um diagrama simplificado dos elementos principais do metabolismo da bactéria Escherichia coli. (O metabolismo é o conjunto das reacçōes químicas que ocorrem numa célula).

As leis básicas e as relações termodinâmicas que são utilizadas para descrever os processos químicos (Fig. 1a) são as mesmas que as utilizadas na descrição dos processos bioquímicos (Fig. 1b). Contudo, nestes últimos, é bem mais limitada a existência de dados termodinâmicos referentes a compostos biológicos, sendo praticamente inexistentes os métodos de previsão e os modelos termodinâmicos aplicados às substâncias de interesse em bioquímica.

A Tabela 1 mostra as principais características que diferenciam os sistemas químicos dos sistemas bioquímicos. Contrariamente ao que acontece nos sistemas químicos os quais envolvem moléculas relativamente simples (esta simplicidade é, no entanto, relativa pois poderão estar envolvidas moléculas tais como a piridina $-\mathrm{C}_{5} \mathrm{H}_{5} \mathrm{~N}-$ ou a quinolina $-\mathrm{C}_{9} \mathrm{H}_{7} \mathrm{~N}-$ que até há bem pouco tempo eram exemplos de moléculas complexas...), os sistemas bioquímicos são caracterizados por uma grande complexidade molecular, sendo frequente encontrar moléculas de peso molecular muito elevado.

TABELA I

Principais características dos sistemas quimicos e dos sistemas bioquímicos

\begin{tabular}{ll}
\hline \multicolumn{1}{c}{ Sistemas químicos } & \multicolumn{1}{c}{ Sistemas bioquimicos } \\
\hline $\begin{array}{l}\text { moléculas "simples" } \\
\text { existência de dados } \\
\text { termofisicos e métodos de } \\
\text { previsão/correlação }\end{array}$ & $\begin{array}{l}\text { grande compexidade molecular } \\
\text { poucos dados termofísicos }\end{array}$ \\
$\begin{array}{l}\text { moléculas de P.M. baixo ou } \\
\text { intermédio }\end{array}$ & $\begin{array}{l}\text { moléculas de P.M. elevado } \\
\text { (Ex.: Miosina }-500 \text { 000) }\end{array}$ \\
$\begin{array}{l}\text { fases bem definidas } \\
\text { energia "térmica" }\end{array}$ & emulsðes \\
(Ex.: petróleo) & energia "quimica" \\
\hline
\end{tabular}

Contudo, os balanços de massa e energia e os princípios termodinâmicos que são utilizados frequentemente na análise dos processos químicos, aplicam-se igualmente aos sistemas bioquímicos. Uma célula pode ser considerada como um reactor químico ao qual se aplicam os usuais balanços de energia e regras da estequiometria.

\section{Termodinâmica bioquímica}

Um exemplo da aplicação de um resultado termodinâmico a um bioprocesso é dado pelo mecanismo de cisão duma molécula de glucose em duas moléculas de ácido láctico, um tipo de fermentação conhecido como glicólise. Este processo faz parte do mecanismo de Embden-Meyerhof-Parnas (EMP), o qual envolve dez reacçōes catalisadas por enzimas e que está representado na Fig. 1b. Na glicólise, a formação do lactato efectua-se através de um mecanismo em que participam o fosfato, assim como o di- e o trifosfato de adenosina
(ADP e ATP, respectivamente), de acordo com a reacção global.

glucose $+2 \mathrm{P}_{\mathrm{i}}+2 \mathrm{ADP}-2$ lactato $+2 \mathrm{ATP}+2 \mathrm{H}_{2} \mathrm{O}$

Para esta reacção a variação da energia de Gibbs padrão é $\Delta \mathrm{G}^{01}=-135.6 \mathrm{~kJ} \mathrm{~mol}^{-1}$ (o estado padrão refere-se à reacção em que reagentes e produtos estão com uma concentração igual a 1 molar, a $25^{\circ} \mathrm{C}$ e a $\mathrm{pH}=7$ ).

Por outro lado, para a reacção correspondente à fermentação anaeróbica em que uma molécula de glucose $\left(\mathrm{C}_{6} \mathrm{H}_{12} \mathrm{O}_{6}\right)$ origina duas moléculas de ácido láctico $\left(\mathrm{C}_{3} \mathrm{H}_{6} \mathrm{O}_{3}\right)$,

\section{glucose $\rightarrow 2$ ácido láctico}

a variação da energia de Gibbs padrão é $\Delta \mathrm{G}^{01}=$ $=-196.6 \mathrm{~kJ} \mathrm{~mol}^{-1}$. Trata-se de uma reacção espontânea, uma vez que se efectua com uma diminuição da energia de Gibbs.

Comparando estas duas equaçð̃es compreende-se que nas células uma grande parte da perda da energia de Gibbs, que ocorre quando a glucose origina o lactato, é conservada sob a forma de ATP. De facto, há um total de $61 \mathrm{~kJ}$ (ou $30.5 \mathrm{~kJ}$ por cada mole de ATP formado) que são conservados, o que corresponde a uma eficiência de cerca de $31 \%[61 / 196.6 \times 100 \%=31 \%]$. A termodinâmica permite explicar, assim, que a principal razão pela qual as células processam as moléculas de glucose (provenientes dos alimentos, por exemplo) é para formarem ATP a partir de ADP e do fosfato. O ATP assim formado conserva uma grande parte da energia contida na molécula original.

As moléculas de ATP funcionam por isso como "reservatórios" de energia química, podendo transferir essa energia através da doação dos seus grupos terminais fosfato de "alta energia". (Esta "alta energia" não se refere à energia da ligação covalente entre os átomos de fósforo e os átomos de oxigénio ou azoto, mas deve interpretar-se como sendo uma energia não localizada na ligação química, reflectindo o conteúdo energético relativo entre os reagentes e os produtos).

Logo que são formadas, as moléculas de ADP e de fosfato são estabilizadas por híbridos de ressonância. Tal não acontece com a molécula de ATP, cuja parte linear polifosfatada a $\mathrm{pH}=7$, tem quatro cargas negativas perto uma das outras que se repelem fortemente. Quando a ligação fosfato terminal é hidrolizada, liberta-se parte desta tensão electrostática.

O ATP é, assim, o meio através do qual as células armazenam temporariamente a energia obtida a partir dos alimentos (ou da luz solar), para utilização posterior tal como na síntese de biopolimeros, transporte de materiais através de membranas, ou na contracção de músculos. É esta conversão directa de energia química em trabalho mecânico, sem a utilização de intermediários, tais como a electricidade ou o vapor, que é característica única dos seres vivos.

\section{Conclusões}

São muito vastas as perspectivas de aplicação da termodinâmica aos sistemas biológicos.

Uma vez que os bioprocessos envolvem frequentemente as emulsð̄es, isto é, fluidos parcialmente ordenados nos 
quais dois líquidos imiscíveis constituem as fases dispersa e contínua, é necessário desenvolverem-se modelos termodinâmicos que permitam descrever os vários diagramas de fase que ocorrem nos sistemas que formam as emulsðes. Existem actualmente alguns desses modelos, baseados em diferentes representaçð̄es das emulsðes, mas infelizmente envolvem um grande número de parâmetros (alguns de significado físico duvidoso) e, mesmo assim, apenas conseguem dar uma representação qualitativa ou semi-quantitativa dos diagramas de fases.

Uma outra área onde a termodinâmica pode dar informação importante é no estabelecimento da estrutura das proteínas. Usando sobretudo técnicas de simulação, é possível estudar qual a configuração geométrica mais provável da molécula de uma proteína. Este problema é de grande importância, pois a configuração assumida por uma proteina (isto é, aquela que minimiza a energia de Gibbs da molécula) determina quais as suas propriedades, havendo uma relação directa entre a estrutura de uma proteina e a sua função. A termodinâmica pode utilizar-se também na determinação das condiçőes onde pode ocorrer o enrolamento das proteínas (recorrendo à estimativa da variação da energia de Gibbs).

De realçar também o contributo que a termodinâmica pode vir a dar em biotecnologia, em áreas tão diversas como, por exemplo, a produção de produtos químicos e farmacêuticos, a produção de alimentos, o tratamento de efluentes e a engenharia biomédica.

Para se passar da fase laboratorial para a fase de produção industrial tem que se dispor de uma grande variedade de propriedades termodinâmicas que, em muitos casos, ainda não existem, impedindo que se faça um projecto correcto tal como é exigido em engenharia. Para solucionar este problema é necessário que se estabeleça um banco de dados de propriedades termofísicas de compostos biologicos e suas misturas, tal como existe para os fluidos mais importantes para a indústria química. Estes dados termodinâmicos (ou métodos de estimativa adequados) são essenciais pois são largamente utilizados em simuladores de processo no projecto e optimização de unidades industriais.

Para o correcto estabelecimento de um banco de dados de propriedades termofísicas de compostos biológicos e de soluções biologicas (principalmente aquosas), é preciso, em primeiro lugar, identificar quais as propriedades termodinâmicas de maior importância (dados de equilíbrio de fases, propriedades interfaciais e coloidais, coeficientes de difusão, viscosidades, densidade, entalpia, etc.).

Em seguida, essas medidas devem efectuar-se em compostos modelo (soluçð̄es aquosas de ribonuclease, hemoglobina, lisózima, cafeína, etc.), sendo compostos seleccionados de acordo com a facilidade da sua obtenção na pureza conveniente, a sua importância bioquímica, a natureza da sua estrutura molecular e, sobretudo, a ausência de problemas de caracterização e estabilidade.

Com a informação assim recolhida é necessário desenvolver métodos de correlação e identificar os modelos teóricos mais promissores para posterior aplicação às misturas de interesse para a biotecnologia. Dentro dos modelos de que a termodinâmica dispōe, são de destacar a termodinâmica contínua e a simulação por computador. Estas técnicas teóricas são potencialmente muito úteis no desenvolvimento de modelos de previsão do comportamento termodinâmico de sistemas fluidos biologicos, os quais são necessários para o projecto e optimização dos bioprocessos.

Uma outra (importante) área de aplicação da termodinâmica é na resolução de problemas de separação, nomeadamente na recuperação de produtos de fermentação utilizando solventes (líquidos ou supercríticos). A aplicação da extracção supercrítica é particularmente promissora na recuperação de compostos biológicos, uma vez que todo o processo de extracção pode ser efectuado a temperaturas próximas da ambiente com solventes não tóxicos (como o $\mathrm{CO}_{2}$ ), sendo minimizados os resíduos de solvente devido à alta volatilidade dos solventes normalmente utilizados.

Pode concluir-se, que é de esperar que num futuro relativamente próximo haja um grande desenvolvimento da termodinâmica bioquímica, tanto do ponto de vista teórico como do experimental. São de esperar grandes avanços deste ramo da termodinâmica, sendo porém essencial que se desenvolva uma colaboração multidisciplinar e cooperativa. 


\section{ventiladores centrifugos}

\section{PARA FLUDOS CORROSUIOS}

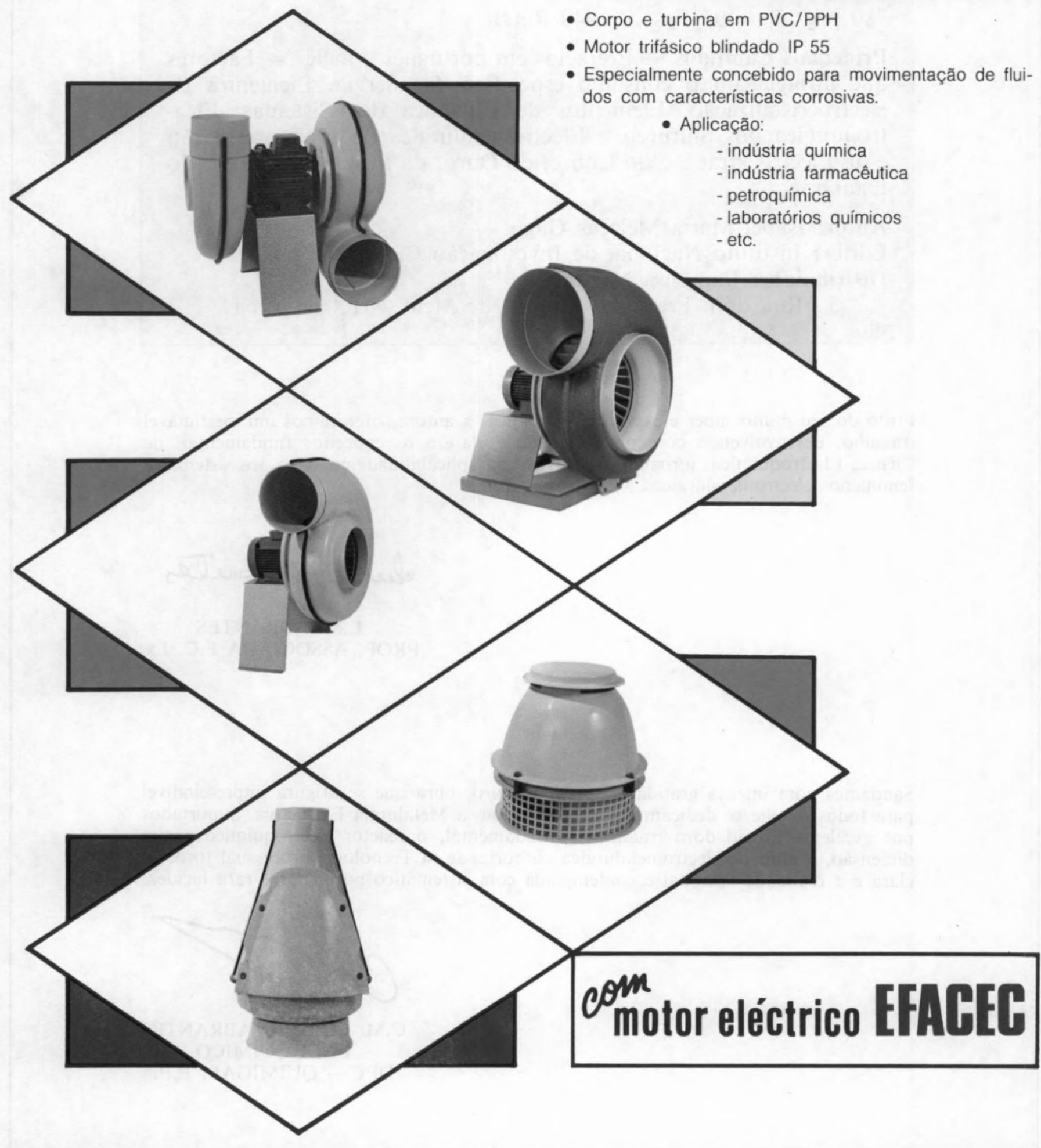

Capital Social 1500000 contos

CRC Porto-n.0 13298

Contribuinte $n .^{\circ} 500091480$

C.A.E. 383100
Divisão VENTILADORES

NORTE: Av. Eng. ${ }^{\circ}$ Frederico Ulrich-Apartado 31-Guardeiras - 4470 MAIA

Tel. 9482210-Telex 25491 EFAMA P

SUL: R. Rodrigo da Fonseca, $76-30^{\circ}-1200$ LISBOA Tels. 530161-563351-Telex 12124 EFALIS P 


\section{«Electrometalurgia das Soluções Aquosas»}

\section{(Princípios Fundamentais)}

(Os Processos Electrometalúrgicos interpretados segundo as suas bases electroquímicas.)

780 págs. 195 figs. 440 Refs.

Principais Capítulos - Prefácios em português e inglês - Factores que influenciam o consumo específico de energia. Elementos de electrocristalização. Elementos de Dinâmica dos Sistemas. Electroquímica dos Sulfuretos. Electrometalúrgica da Electrorefinação e da Electroextracção do Cobre, do Ouro, da Prata, do Zinco e do Estanho.

\section{Autor: Isabel Maria Meleças Gago}

Editor: Instituto Nacional de Investigação Científica

Distribuidor: Imprensa Nacional

5 - Rua dom Francisco Manuel de Melo - 1000 Lisboa

Fruto do seu muito saber e experiência didática, a autora, oferece-nos um inestimável trabalho, desenvolvendo com profundidade e clareza os conceitos fundamentais de Ciência Electroquímica, tornando-os "vivos» na aplicabilidade concreta aos sistemas e fenómenos electrometalúrgicos.

\section{Quisetestreetes}

L.M. ABRANTES

PROF. ASSOCIADA F.C. Lx.

Saudamos com imensa gratidão o presente livro, obra que se afigura imprescindível para todos os que se dedicam e preocupam com a Metalurgia Extractiva. Suportados por excelente e cuidadoso tratamento fundamental, o reactor electroquímico ganha dimensão, a unidade electrometalúrgica corporiza-se, a Tecnologia processual torna-se clara e a realidade naciơnal é contemplada com sistemático pormenor e rara lucidez.

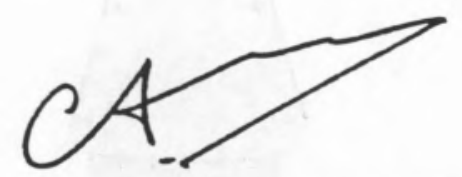

C.M. COELHO ABRANTES ENG. QUÍMICO

DPC - QUIMIGAL, E.P. 